\title{
Accuracy of preoperative prediction of malignancy in ovarian mass by ultrasound examination and CA 125 serum level
}

\author{
Hossam Hassan Aly Hassan El Sokkary*
}

\begin{abstract}
:
Background: Ovarian cancer is the second most common malignancy of the female reproductive system and one of the leading lethal gynecologic malignancies. Screening of ovarian cancer in certain high risk groups is very important due to unspecificity and late appearance of symptoms. Its risk factors include positive family history, older age of menopause and low parity as pregnancy protects against ovarian cancer. Objectives: to compare the accuracy of preoperative prediction of malignancy in ovarian mass by morphological ultrasound (US) examination, Doppler indices and CA 125 serum level with the result of histopathological examination mass after laparotomy. Methods: One hundred and four cases of ovarian masses predicted to be malignant by US examination and CA 125 serum level were subjected to laparotomy and histopathological examination. The main outcome measures in the ovarian masses were: a- the US signs of malignancy [ such as solid mass, multiple septation in cystic mass, mixed solid and cystic components, thick cyst wall (> $3 \mathrm{~mm}$ ), nodule in a cyst wall ] , b- Doppler indices(resistance index and pulsatility index) , c- CA125 serum level, and d- histopathological examination findings after laparotomy. Results: The histopathology identified 20 benign (B) and 84 malignant (M) ovarian masses. The benign tumors were $9(45 \%)$ endometroitic cyst, $6(30 \%)$ pseudomucinous cyst adenoma and $5(25 \%)$ serous cyst adenoma. The malignant ones included $43(51.2 \%)$ papillary serous cyst adenocarcinoma $18(21.4 \%)$ endometrioid adenocarcinoma , 10(11.9\%) pseudomucinous cyst adenocarcinoma, $5(5.9 \%)$ clear cell adenocarcinoma, 2(2.4\%) papillary serous borderline cyst adenocarcinoma, 2(2.4\%) borderline serous adenocarcinoma, $1(1.2 \%)$ serous adenocarcinoma, 1(1.2\%) borderline endometroid adenocarcinoma, 1(1.2\%) dysgerminoma and 1(1.2\%) Pseudomucinous borderline cyst adenocarcinoma]. The US showed no morphological signs of malignancy in 10 [9.6\% (9 M vs. 1 B)] masses, thick cyst wall and mixed solid \& cystic components $1(1 \%) \mathbf{M}$; thick cyst wall1 and nodule in the cyst wall $1(1 \%) \mathbf{M}$, mixed solid and cystic components $15[14.4 \%$ (14 M vs. 1 B)], solid components $17(16.3 \%)$ M, thick cyst wall (> $3 \mathrm{~mm}) 27[26 \%$ (10 $\mathbf{M}$ vs. $17 \mathbf{B})]$ and nodules in the cyst wall in $33[31.7 \%$ (32 $\mathbf{M}$ vs. 1 B)] masses. Doppler studies of ovarian mass vasculature showed that $<0.4$ resistance index and $<1$ pulsatility index prevailed significantly in 83 and 82 malignant masses respectively $(P<0.001)$ while $C A 125$ serum cutoff level $30 \mathrm{lU} / \mathrm{ml}$ alone failed to differentiate between the benign and malignant masses Conclusion: using CA125 serum cutoff level $30 \mathrm{IU} /$ $\mathrm{ml}$ combined with US grey scale or color Doppler examination can discriminate between benign and malignant adnexal masses especially in positive Doppler indices.
\end{abstract}

\section{INTRODUCTION}

Ovarian cancer $(\mathrm{OC})$ is the second most malignancies. ${ }^{(1)}$ The disease is more common common malignancy of the female in industrialized nations, with the exception of reproductive system and one of the Japan. In the United States, females have $1 \%$ leading causes of death among gynaecologic to $2.5 \%$ (1 out of $40-60$ women) lifetime *Department of Obstetrics and Gynecology, Faculty of Medicine, Alexandria University. 
chance of developing OC. Older women are at highest risk. More than half of the deaths from $\mathrm{OC}$ occur in women between 55 and 74 years of age and approximately one quarter of $\mathrm{OC}$ deaths occur in women between 35 and 54 years of age.(2) There are no statistics that describe disease incidence in Egypt. Signs and symptoms of $\mathrm{OC}$ are frequently absent early and when they exist they may be subtle. In most cases, the symptoms persist for several months before being recognized and diagnosed.(3) The five-year survival rate for all stages of $\mathrm{OC}$ is $47 \%$.(4) For cases where a diagnosis is made early in the disease, when the cancer is still confined to the primary site, the five-year survival rate is $92.7 \% .^{(5)}$

So prognosis is good for women diagnosed at an early stage, whereas the majority, diagnosed at later stages, is likely to survive less than 5 years. ${ }^{(6)}$

Symptoms as bloating, fullness, and pressure in the abdomen are the most prominent symptoms. Pain and fatigue are also important, followed by problems in urination and constipation. (7) Ovarian cancer is neither an asymptomatic disease nor a socalled 'silent killer'. Recent studies have demonstrated that patients at all stages of the disease have symptoms. ${ }^{(8,18,19)}$ Examination can reveal abdominal or pelvi-abdominal mass only in the late stages and bimanual pelvic examination can reveal adenexal mass or fullness. ${ }^{(9,20)}$

Studies exploring the value of screening those women for OC are lacking and urgently required. Even though population-based screening for $\mathrm{OC}$ is not recommended, and although there is no level of evidence that this group of women should undergo screening, it seems prudent that, until evidence is available, measurement of CA 125 levels and transvaginal ultrasound should be undertaken at least on yearly basis. ${ }^{(21)}$

CA125 is still the most extensively studied biomarker for possible use in the early detection of $\mathrm{OC}$, and has proved valuable in both detection and disease monitoring. ${ }^{(23,24)}$ CA125 is elevated in the serum of most 
women with $\mathrm{OC}$, but pre-operative serum levels of CA125 are below the conventional cutoff level of $35 \mathrm{U} / \mathrm{ml}$ in roughly $50 \%$ of clinically detected stage I cases ${ }^{(25)}$ and in the majority of women with occult cancers identified at prophylactic surgery. ${ }^{(26)}$

Using vaginal ultrasound examination can add to the predictive value of CA125. US morphological signs of malignancy include large ovarian volume more than $18 \mathrm{ml}$ before menopause and $8 \mathrm{ml}$ after, thick cyst wall, solid component in ovarian mass, mixed solid and cystic component, nodule in the cyst wall and abnormal vascular pattern proved by Doppler study (27,28,29).

\section{Objectives:}

To evaluate the accuracy of preoperative prediction of malignancy in ovarian mass by the morphological ultrasound examination, Doppler indices and CA 125 serum level.

\section{Methods:}

Following approval by Alexandria Faculty of Medicine Institutional Ethics Committee, 104 patients with ovarian masses that fulfilled the inclusion criteria attending the outpatient clinic of Oncology Department of El-Shatby University Hospital were included in the study after taking their consents. The study was the "One-shot prospective case study" without control group. The main inclusion criteria were ovarian mass with one or more of the followings a- Ultrasonographic (US) signs of malignancy [ such as solid component, mixed solid and cystic component, nodule in the cyst wall, thick cyst wall (more than $3 \mathrm{~mm}$ ) ], b- Doppler studies of ovarian mass vessels (including resistance index $(\mathrm{RI})$ and pulsatilty index $(\mathrm{PI})$ with a cut level values of less than 0.4 for $\mathrm{Rl}$ and less than 1 for PI.(31,32) For enrolment in the study there should be: 1- at least one positive US sign whether morphological appearance or Doppler indices. 2- This positive US sign must be combined with CA 125 serum level more than $30 \mathrm{u} / \mathrm{ml}^{(30)}$ Patients with these criteria were admitted and subjected to laparotomy and histopathological examination of the ovarian masses. The women were 
examined with both real-time $3.5-5 \mathrm{MHz}$ Shatby University Hospital and transabdominal transducer and 5.5-7 $\mathrm{MHZ}$ histopathological examination was done to all vaginal transducer. ovarian masses at the Clinical Pathology

Laparatomy was done to all cases at El- Department of the Main University Hospital.

\section{Table (1) Sample size of one group according to disease prevalence}

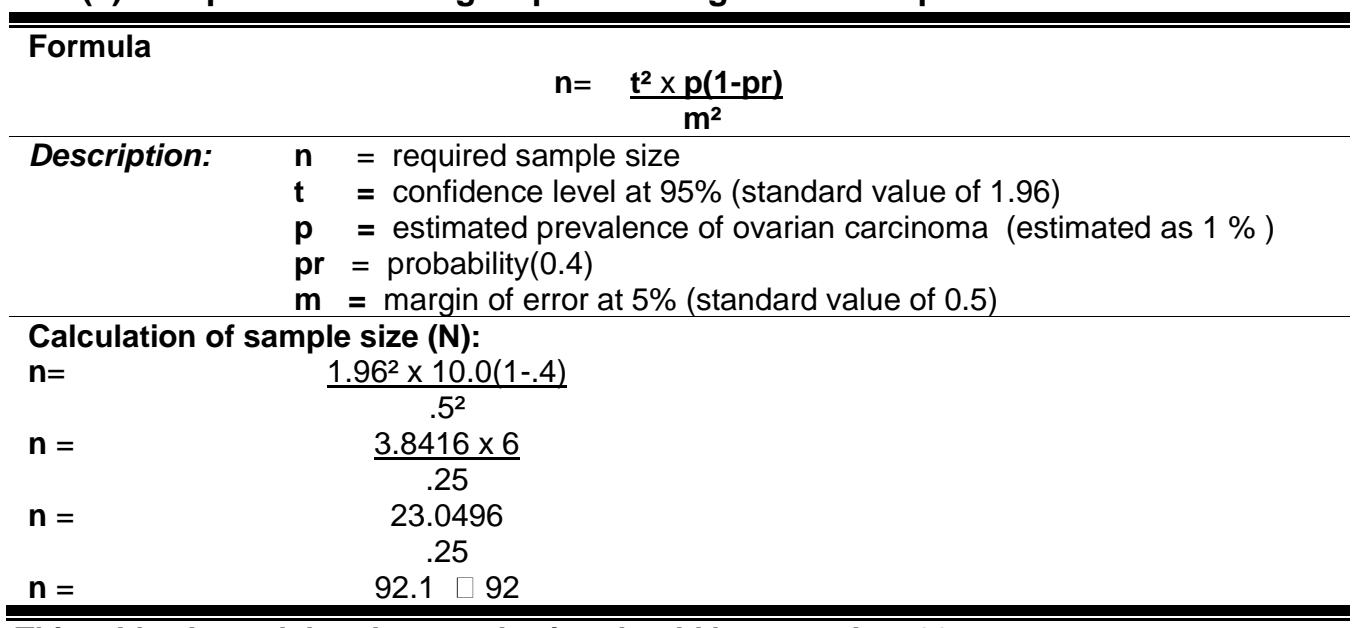

This table showed that the sample size should be more than 92 cases.

\section{RESULTS}

Histopathology reports of the ovarian masses showed that 43 masses were papillary serous cystadenocarcinoma, 2 papillary serous borderlines cystadenocarcinoma, $\quad 1 \quad$ serous adenocarcinoma, 2 borderlines serous adenocarcinoma, $18 \quad$ endometrioid adenocarcinoma, 1 borderline endometroid adenocarcinoma, 10 pseudomucinous cyst adenocarcinoma, 1 pseudomucinous borderline cyst adenocarcinoma, 1 dysgerminoma, 5 clear cell adenocarcinoma, 5 serous, 6 pseudomucinous cyst adenoma, and 9 endometriotic cysts. Malignant masses were 84 and benign ones were 20 . Regarding the ultrasonographic signs, 10 cases showed any morphological sign of malignancy, 17 showed solid components, 15 
mixed solid and cystic components, 33 nodule nodule in the cyst wall. Doppler studies of in the cyst wall, 27 thick cyst wall $(>3 \mathrm{~mm}), 1 \quad$ tumor vasculature showed that the resistance thick cyst wall and mixed solid and cystic index was less than 0.4 in 83 cases and the component and 1 showed thick cyst wall and pulsatility index was less than 1 in 82 cases.

Table (2): Distribution of the studied ovarian masses according to the histopathological diagnosis.

\begin{tabular}{|c|c|c|c|c|}
\hline \multirow[t]{2}{*}{ Diagnosis } & & \multicolumn{2}{|c|}{ Ovarian mass } & \multirow[t]{2}{*}{ Total } \\
\hline & & Malignant & Benign & \\
\hline Borderline endometroid adenocarcinoma & $\begin{array}{l}\text { no. } \\
\%\end{array}$ & $\begin{array}{c}1 \\
1.2 \%\end{array}$ & $\begin{array}{c}0 \\
.0 \%\end{array}$ & $\begin{array}{c}1 \\
1.0 \%\end{array}$ \\
\hline Clear cell adenocarcinoma & $\begin{array}{l}\text { no. } \\
\%\end{array}$ & $\begin{array}{c}5 \\
5.9 \%\end{array}$ & $\begin{array}{c}0 \\
.0 \%\end{array}$ & $\begin{array}{c}5 \\
4.8 \%\end{array}$ \\
\hline Dysgerminoma & $\begin{array}{l}\text { no. } \\
\%\end{array}$ & $\begin{array}{c}1 \\
1.2 \%\end{array}$ & $\begin{array}{c}0 \\
.0 \%\end{array}$ & $\begin{array}{c}1 \\
1.0 \%\end{array}$ \\
\hline Endometriod adenocarcinoma & $\begin{array}{l}\text { no. } \\
\%\end{array}$ & $\begin{array}{c}18 \\
21.4 \%\end{array}$ & $\begin{array}{c}0 \\
.0 \%\end{array}$ & $\begin{array}{c}18 \\
17.3 \%\end{array}$ \\
\hline Endometroitic cyst & $\begin{array}{l}\text { no. } \\
\%\end{array}$ & $\begin{array}{c}0 \\
.0 \%\end{array}$ & $\begin{array}{c}9 \\
45 \%\end{array}$ & $\begin{array}{c}9 \\
8.7 \%\end{array}$ \\
\hline $\begin{array}{l}\text { Pseudomucinous border line cyst } \\
\text { adenocarcinoma }\end{array}$ & no. & 1 & 0 & 1 \\
\hline Pseudomucinous cyst adenocarcinoma & $\begin{array}{c}\% \\
\text { no. } \\
\%\end{array}$ & $\begin{array}{c}1.2 \% \\
10 \\
11.9 \%\end{array}$ & $\begin{array}{c}.0 \% \\
0 \\
.0 \%\end{array}$ & $\begin{array}{c}1.0 \% \\
10 \\
9.6 \%\end{array}$ \\
\hline $\begin{array}{l}\text { Papillary serous border line cyst } \\
\text { adenocarcinoma }\end{array}$ & no. & 2 & 0 & 2 \\
\hline Papillary serous cyst adenocarcinoma & $\begin{array}{c}\% \\
\text { no. } \\
\%\end{array}$ & $\begin{array}{c}2.4 \% \\
43 \\
51.2 \%\end{array}$ & $\begin{array}{c}.0 \% \\
0 \\
.0 \%\end{array}$ & $\begin{array}{c}2.0 \% \\
43 \\
41.3 \%\end{array}$ \\
\hline Pseudomucinous cyst adenoma & $\begin{array}{l}\text { no. } \\
\%\end{array}$ & $\begin{array}{c}0 \\
.0 \%\end{array}$ & $\begin{array}{c}6 \\
30 \%\end{array}$ & $\begin{array}{c}6 \\
5.7 \%\end{array}$ \\
\hline Serous cyst adenocarcinoma & $\begin{array}{l}\text { no. } \\
\%\end{array}$ & $\begin{array}{c}1 \\
1.2 \%\end{array}$ & $\begin{array}{c}0 \\
.0 \%\end{array}$ & $\begin{array}{c}1 \\
1.0 \%\end{array}$ \\
\hline Serous cyst adenocarcinoma border line & $\begin{array}{l}\text { no. } \\
\%\end{array}$ & $\begin{array}{c}2 \\
2.4 \%\end{array}$ & $\begin{array}{c}0 \\
.0 \%\end{array}$ & $\begin{array}{l}2 \\
1.9 \%\end{array}$ \\
\hline Serous cyst adenoma & $\begin{array}{l}\text { no. } \\
\%\end{array}$ & $\begin{array}{c}0 \\
.0 \%\end{array}$ & $\begin{array}{c}5 \\
25.0 \%\end{array}$ & $\begin{array}{l}5 \\
4.8 \%\end{array}$ \\
\hline Total & $\begin{array}{l}\text { no. } \\
\%\end{array}$ & $\begin{array}{c}84 \\
100.0 \%\end{array}$ & $\begin{array}{c}20 \\
100.0 \%\end{array}$ & $\begin{array}{c}104 \\
100.0 \%\end{array}$ \\
\hline $\begin{array}{l}X^{2} \\
P\end{array}$ & & $\begin{array}{c}84.0 \\
0.0001^{*}\end{array}$ & & \\
\hline
\end{tabular}


Table (2) described the Using CA125 serum level and histopathological diagnosis of the studied ulrasonographic examination of ovarian patients. Malignant cases were 84 and masses, there was a significant difference benign cases were only 20. $(p=0.0001)$. between the benign and malignant cases.

Table (3) Distribution of the studied ovarian masses according to the ultrasonographic morphological signs.

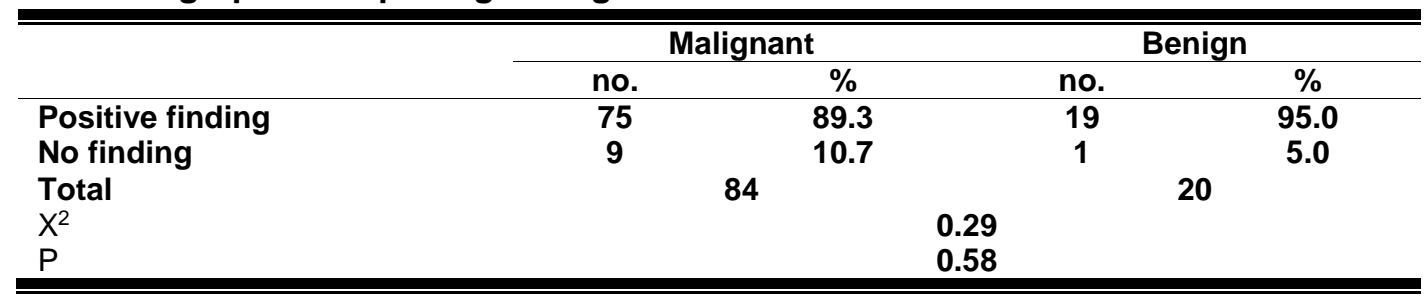

Table (3) showed that by using ultrasound in 75 (89.3\%) and 19 (95\%) malignant and alone, the ultrasonographic morphological benign masses with no significant difference signs of malignancies were respectively seen in-between $(p=0.58)$

Table (4): Comparison between the mean age, resistance index, pulsatility index and CA 125 of the benign and malignant cases

\begin{tabular}{lcccccc}
\hline \hline & & no & Mean & S.D. & t-test & P \\
\hline Age & Malignant & 84 & 51.13 & 5.566 & 39.970 & $0.0032^{*}$ \\
& Benign & 20 & 42.45 & 5.306 & & \\
Resistance index & Malignant & 83 & .323 & .0979 & 103.046 & $.0001^{*}$ \\
& Benign & 20 & .575 & .1070 & & \\
Pulsatility index & Malignant & 82 & .72 & .150 & 102.356 & $.0001^{*}$ \\
& Benign & 20 & 1.11 & .176 & & \\
CA 125 & Malignant & 84 & 79.98 & 25.328 & 1.957 & .165 \\
& Benign & 20 & 70.45 & 34.916 & & \\
\hline \hline
\end{tabular}

Table (4) showed that there was no malignant cases regarding CA125 level, significant difference between benign and but there were significant differences 
between them with respect to age, pulsatility malignancy induces new blood vessels index and resistance index. Eighty three formation that lack muscle wall which malignant ovarian masses showed resistance decreases resistance to blood flow and index Less than 0.4 and 82 malignant cases increases diastolic blood flow and this is showed pulsatility index less than 1 as shown by Doppler indices of the study.

Table (5) Comparison between benign and malignant cases regarding the ultrasonographic malignant signs.

\begin{tabular}{|c|c|c|c|c|c|}
\hline \multicolumn{3}{|c|}{ Ultrasonographic signs } & \multicolumn{2}{|c|}{ Group } & \multirow[b]{2}{*}{ Total } \\
\hline & & & Malignant & Benign & \\
\hline & \multirow[t]{2}{*}{ Mixed solid and cystic components } & no. & 14 & 1 & 15 \\
\hline & & $\%$ & 16.7 & 5.0 & 14.4 \\
\hline & \multirow[t]{2}{*}{ No suspicious sign of malignancy } & no. & 9 & 1 & 10 \\
\hline & & $\%$ & 10.7 & 5.0 & 9.6 \\
\hline & \multirow[t]{2}{*}{ Nodule in the cyst wall } & no. & 32 & 1 & 33 \\
\hline & & $\%$ & 38.1 & 5.0 & 31.7 \\
\hline & \multirow[t]{2}{*}{ Solid component } & no. & 17 & 0 & 17 \\
\hline & & $\%$ & 20.2 & 0.0 & 16.3 \\
\hline & \multirow[t]{2}{*}{ Thick cyst wall (more than $3 \mathrm{~mm}$ ) } & no. & 10 & 17 & 27 \\
\hline & & $\%$ & 11.9 & 85.0 & 26.0 \\
\hline & \multirow[t]{2}{*}{ Thick cyst wall, nodule in wall } & no. & 1 & 0 & 1 \\
\hline & & $\%$ & 1.2 & 0.0 & 1.0 \\
\hline & \multirow{2}{*}{$\begin{array}{l}\text { Thick cyst wall, Mixed solid and } \\
\text { cystic components }\end{array}$} & no. & 1 & 0 & 1 \\
\hline \multirow{3}{*}{ Total } & & $\%$ & 1.2 & 0.0 & 1.0 \\
\hline & & no. & 84 & \multirow{2}{*}{$\begin{array}{c}20 \\
100.0\end{array}$} & \multirow[t]{2}{*}{104} \\
\hline & & $\%$ & 100.0 & & \\
\hline
\end{tabular}

Table (5) showed that the frequency of the US ultrasonographic malignant sign was present morphological signs of malignancy among in 17 malignant cases while it was not present cass of the study. The solid component in any benign case. 


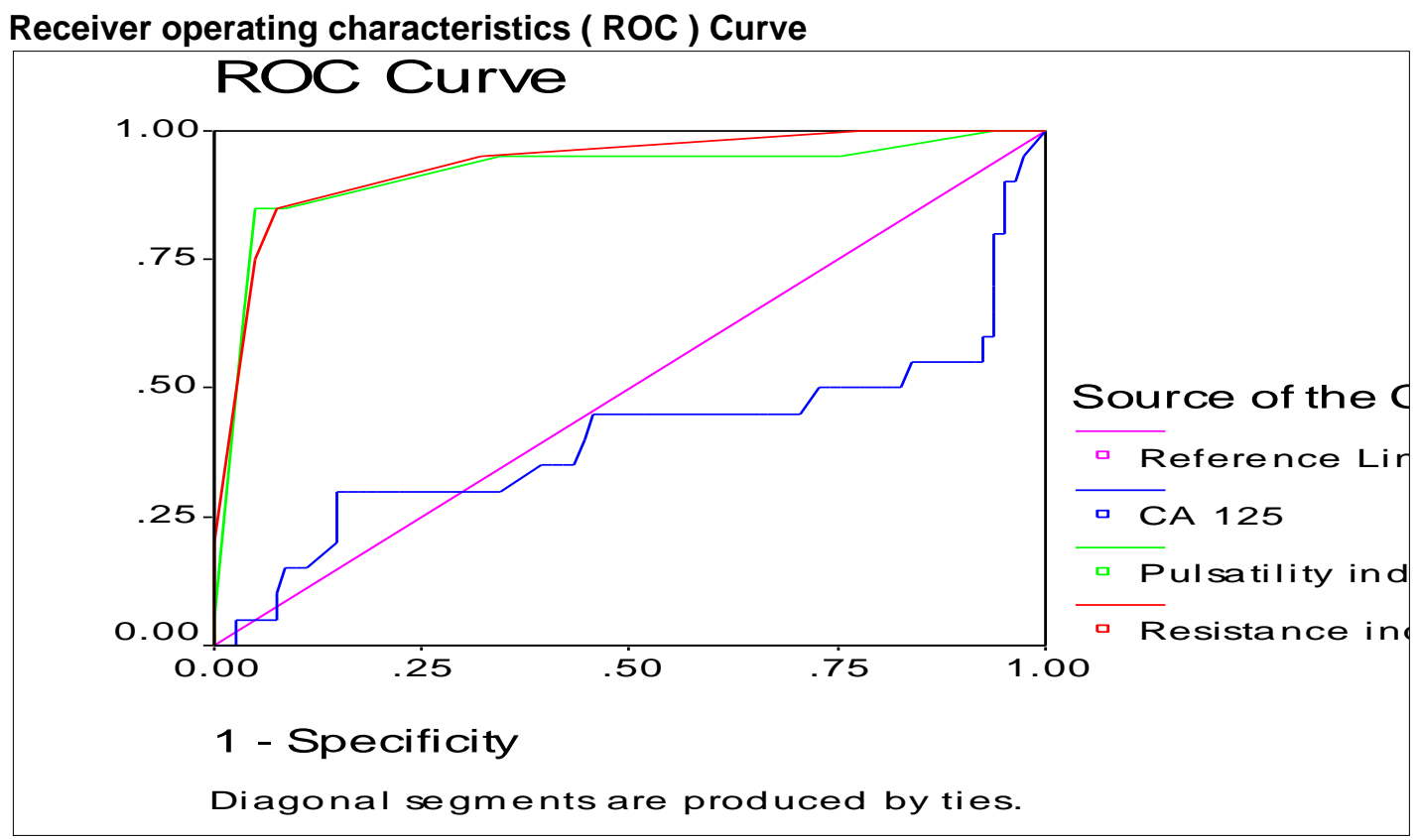

Table (6) Area under the ROC Curve

\begin{tabular}{|c|c|c|c|c|c|}
\hline \multirow[t]{2}{*}{ Test Result Variable(s) } & \multirow[t]{2}{*}{ Area } & \multirow{2}{*}{$\begin{array}{l}\text { Std. } \\
\text { Error(a) }\end{array}$} & \multirow{2}{*}{$\begin{array}{l}\text { Asymptotic } \\
\text { Sig.(b) }\end{array}$} & \multicolumn{2}{|c|}{$\begin{array}{l}\text { Asymptotic } 95 \% \text { Confidence } \\
\text { Interval }\end{array}$} \\
\hline & & & & Lower Bound & Upper Bound \\
\hline Resistance index & .933 & .032 & .000 & .870 & .996 \\
\hline Pulsatility index & .916 & .044 & .000 & .830 & 1.003 \\
\hline CA 125 & .402 & .086 & .178 & .233 & .572 \\
\hline
\end{tabular}

The test result variable(s): resistance state (benign) group. Statistics may be index, pulsatility index, CA 125 had at least biased. a Under the nonparametric one tie between the positive actual state assumption b Null hypothesis: true area = (malignant) group and the negative actual 0.5 . 


\section{Table (7) Coordinates of the ROC curve}

\begin{tabular}{lccc}
\hline \hline & $\begin{array}{c}\text { Positive if Greater } \\
\text { Than or Equal }\end{array}$ & & \\
Test Result Variable(s) & To(a) & Sensitivity & Specificity \\
\hline Resistance index & .450 & .850 & .074 \\
Pulsatility index & .65 & .950 & .753 \\
CA 125 & 36.00 & .800 & .951 \\
\hline \hline
\end{tabular}

ROC curve showed that CA125 was neither sensitive nor specific to differentiate between benign and malignant ovarian cases while both pulsatility index and resistance index were specific and sensitive to differentiate between them

\section{DISCUSSION}

Differentiation between benign and malignant adnexal masses is very important before management. If the mass shows high malignancy index, the management includes vertical midline incision, aspiration cytology, complete abdominal inspection and palpation, total abdominal hysterectomy with bilateral salpingoopherectomy, omentectomy, random peritoneal biopsy as well as pelvic and paraaortic lymph node sampling. ${ }^{(33)}$

Differentiating benign from malignant tumors might be achieved by several methods such as clinical signs and symptoms, serum CA 125 and ultrasound. ${ }^{(34)}$

Nonetheless, using one item alone to differentiate between benign and malignant cases shows low positive predictive value. For example, in predicting malignancy in ovarian tumors, abdominal ultrasonography had a positive predictive value of $39 \%$ and a negative predictive value of $94 \%$. If a negative sonogram had been relied upon, $6 \%$ of malignant ovarian tumors in postmenopausal women might have been missed.(35)

Also, serum levels of CA125 have been used widely for distinguishing benign from malignant pelvic masses. However, CA125 is elevated in only about half of stage I/II ovarian cancer patients. Lowering the cutoff of CA125 less than $30 \mathrm{IU} / \mathrm{ML}$ would increase its sensitivity in detecting 
cancer but result in many false positives in patients with benign conditions. ${ }^{(36)}$

In the study of van Nagell et al, the transvaginal grey scale US had a sensitivity of $85.0 \%$, specificity $98.7 \%$, a positive predictive value of $14.01 \%$, and a negative predictive value of $99.9 \%$.(37) Tailor et al using CA125 serum level and morphological vaginal ultrasonographic examination showed that sensitivity of ultrasound screening was $92 \%$ and the specificity was $97.8 \% .{ }^{(38)}$ Varras concluded that the combination of physical examination with serum CA-125 levels and pelvic ultrasound scan seemed to improve the sensitivity and specificity of predicting the adnexal malignancies in postmenopausal women. In contrast, in premenopausal women, the consideration of CA-125 levels with Doppler ultrasonographic findings might confuse the differential diagnosis of ovarian masses. (39)

In the current study, we attempted to use the combination of the ultrasonographic morphological appearance, Doppler indices and CA125 serum level to differentiate between benign and malignant ovarian masses .Our results revealed that using the ultrasound grey scale examination together with Doppler indices of mass vascularity (at least one of them is positive) combined with CA125 serum cutoff level more than 30 IU/ML succeeded significantly to differentiate between the benign $(n=20)$ and malignant $(n=84)$ ovarian masses $(p=0.0001)$. Using the ultrasound morphological picture alone failed to differentiate between benign and malignant ovarian masses $(p=0.58)$. The malignant morphological ultrasound signs have been seen in 75 out of 84 malignant patients and all benign (20) cases except for one. Solid component ultrasonographic sign was the most accurate sign in the differentiation between benign and malignant ovarian masses as it was present in 17 malignant cases while it was seen in either benign case.

As regards the Doppler indices, both 
pulsatility index and resistance index were

sensitive and specific in the differentiation

between both benign and malignant groups

In the same context, CA125 serum cutoff

level more than $30 \mathrm{IU} / \mathrm{ml}$ level was not significantly either sensitive or specific enough to discriminate between the two groups.

\section{CONCLUSION}

From the current study, it is concluded that using CA125 with serum cutoff level > $30 \mathrm{IU} / \mathrm{ml}$ combined with ultrasonographic grey scale or color Doppler examination can effectively discriminate between benign and malignant adnexal masses especially with positive Doppler indices.

\section{REFERENCES}

1. Malik A. Maternal Deaths in a tertiary health care centre of Odisha. Obstet Gynaecol Today. 1997; 11: 17.

2. Stöppler C, Shiel J, William C. Ovarian cancer symptoms, early warning signs, and risk factors. Medicine Net. 2011; 88:400-2

3. Piek JM, Van Diest PJ, Verheijen RH. Ovarian carcinogenesis: an alternative hypothesis. Adv. Exp. Med. Biol.2008; 622: 79-87.

4. Johannes, Laura. Test to Help Determine if ovarian masses are cancer. Wall Street J. 2010; 3:1-22.

5. Edwards BK, Howe HL, Ries LAG I. Annual report to the nation on the status of cancer. Cancer .2002; 94:2766-72.

6. Ries LAG, Kosary CL, Hankey BF, Miller BA, Harras A, Edwards BK. SEER cancer statistics review, National Cancer Institute.1997; 97:2789.

7. Goff BA, Mandel LS, Muntz HG, Melancon $\mathrm{CH}$. Ovarian cancer diagnosis: Results of a national ovarian cancer survey. Cancer. 2000; 89:2068-75.

8. Luesley D. The clinical presentation of ovarian carcinoma. In: Blackledge GRP, Jordon JA, Shingleton HM, eds. Textbook of gynecological cancers. London: WB Saunders, 1991:152-3.

9. Riman T, Persson I, Nilsson S. Hormonal aspects of epithelial ovarian cancer: review of epidemiological evidence. Clin Endocrinol (Oxf). 1998; 49:695-707.

10. Booth M, Beral V, Smith P. Risk factors for ovarian cancer: a case-control study. Br J Cancer. 1989; 60:592-8.

11. Tsilidis KK, Allen NE, Key TJ, Dossus L, Lukanova A, Bakken $K$, et al. Oral contraceptive use and reproductive factors and risk of ovarian cancer in the European Prospective Investigation into Cancer and Nutrition. Br J Cancer. 2011; 105(9):1436-42.

12. Gayther SA, Pharoah PD. The inherited genetics of ovarian and endometrial cancer. Curr Opin Genet Dev. 2010; 20(3):231-8.

13. Salehi F, Dunfield L, Phillips KP, Krewski D, Vanderhyden BC Risk factors for ovarian cancer: an overview with emphasis on hormonal factors. Toxicol Environ Health B Crit Rev. 2008;11(34):301-21.

14. Sueblinvong T, Carney ME. Current understanding of risk factors for ovarian cancer. Curr Treat Options Oncol. 2009; 10(1-2):67-81. 
15. Huncharek M, Geschwind J, Kupelnick B. Perineal application of cosmetic talc and risk of invasive epithelial ovarian cancer: a meta-analysis of 11,933 subjects from sixteen observational studies. Anticancer Research. 2003; 23(2C):1955-60

16. Schouten LJ, Rivera C, Hunter DJ, Spiegelman D, Adami HO, Arslan A, et al. Height, body mass index, and ovarian cancer: a pooled analysis of 12 cohort studies. Cancer Epidemiol

Biomarkers Prev. 2008; 17(4):902-12.

17. Borgfeldt $\mathrm{C}$, Andolf $\mathrm{E}$. Cancer risk after hospital discharge diagnosis of benign ovarian cysts and endometriosis. Acta Obstet Gynecol Scand. 2004; 83(4):395400.

18. Hamilton W, Peters TJ, Bankhead C, Sharp D. Risk of ovarian cancer in women with symptoms in primary care: population based case-control study. BMJ. 2009;339:b2998-

19. Rossing MA, Wicklund KG, CushingHaugen KL, Weiss NS. Predictive Value of symptoms for early detection of ovarian cancer. JNCI J Natl Cancer Inst. 2010; 102(20): 1599.

20. National Collaborating Centre for Cancer. Ovarian cancer. The recognition and initial management of ovarian cancer. London (UK): National Institute for Health and Clinical Excellence (NICE). 2011;122:289.

21. Denny L, Hacker NF, Gori J, Jones III HW, Ngan HYS, Pecorelli S. Staging classification and clinical practice. Guidelines for Gynecologic Cancers. 2000;70:207-312.

22. Menon U, Jacobs IJ. Ovarian cancer screening in the general population: current status. Int $\mathrm{J}$ Gynecol Cancer. 2001; 11: 3-6

23. Kenemans $P$, Yedema CA, Bon GG, Von Mensdorff-Pouilly S. CA 125 in gynecological pathology. Eur J Obstet Gynecol Reprod Biol. 1993; 1, 2:115-24.

24. Jacobs IJ, Menon U. Progress and challenges in screening for early detection of ovarian cancer. Mol Cell Proteomics. 2004;4:355-66.

25. Nathalie Scholler, Nicole CA-125 as tumor markers for epithelial ovarian carcinoma. Urban Cancer. 2001; 92(11):2837-44.

26. Olivier RI, Lubsen-Brandsma MA, Verhoef S, Van Beurden M. CA125 and transvaginal ultrasound monitoring in high-risk women cannot prevent the diagnosis of advanced ovarian cancer. Gynecol Oncol. 2006; 100(1):20-6.

27. Sassone AM, Timor-Tritsch IE, Artner A, Westhoff C, Warren W. Transvaginal sonographic characterization of ovarian disease. Obstet Gynecol.1991; 78:70-76.

28. De Priest PD, Shenson D, Fried A. morphology index based on sonographic findings in ovarian cancer. Gynecol Oncol. 1993; 51:7-11.

29. Kurjak A, Zalud I, Alfirevic Z. Evaluation of adnexal masses with transvaginal color ultrasound. J Ultrasound Med 1991; 10: 295-299.

30. Sobiczewski P, Dańska-Bidzińska A, Rzepka J, Kupryjańczyk J, Gujski M, et al. Evaluation of selected ultrasonographic parameters and marker levels in the preoperative differentiation of borderline ovarian tumors and ovarian cancers. Gynecol Obstet. 2012; 286(6): 1513-19.

31. Bourne T, Campbell S, Steer C, Whitehead M, Collins WP. Transvaginal color flow imaging: a possible new screening for ovarian cancer. Br Med J. 1989; 299:1367-70.

32. Kurjak A, Zanid I, Alfirevic Z. Evaluation of adnexal masses with transvaginal color ultrasound. J Ultrasound Med. 1991; 10:296-7.

33. Gershenson DM. Management of early ovarian cancer: germ cell and sex cordstromal tumors. Gynecol Oncol 1994; 55: 62.

34. Mousavi AS, Sassone, Timmerman D; 
Erdogan N. Development Panel on Ovarian Cancer, Asian Pacific J Cancer Prev.2009; 10: 139-42.

35. Hill T. Power Doppler of abnormal vessels within an ovarian carcinoma. Family practice journal. 2003; 15: 9.

36. Jacobs I, Bast RC, Jr. The CA 125 tumour-associated antigen: a review of the literature. Hum Reprod. 2000; 4: 1-12.

37. Van Nagell JR Jr, DePriest PD, Ueland FR, DeSimone CP, Cooper AL, McDonald JM, Pavlik EJ, Kryscio RJ. Ovarian cancer screening with annual transvaginal sonography, Cancer. 2007; 109(9):1887-96.

38. Tailor A, Bourne TH, Campbell S, Okokon E, Dew T, Collins WP. Results from an ultrasound-based familial ovarian cancer screening clinic: a 10-year observational study, Ultrasound Obstet Gynecol. 2003; 21(4):378-85.

39. Varras M. Benefits and limitations of ultrasonographic evaluation of uterine adnexal lesions in early detection of ovarian cancer. Clin Exp Obstet Gynecol. 2004; 31(2):85-98. 